\title{
STRATEGI SELF PRESENTATION PADA REMAJA PENGGUNA INSTAGRAM
}

\author{
Trisna Septia Ningsih dan Gumi Langerya Rizal \\ Jurusan Psikologi, Universitas Negeri Padang \\ Email: trisnaseptia36@gmail.com, gumi.langerya@gmail.com
}

\begin{abstract}
Abstrak
Penelitian ini bertujuan untuk melihat bagaimana strategi yang dilakukan remaja dalam melakukan self presentation dan juga apakah terdapat perbedaan pada remaja dalam melakukan strategi self presentation berdasarkan tingkatan remaja. Karena masing-masing remaja memiliki strategi tersendiri dalam memperlihatkan dirinya di sosial media instagram. Metode penelitian yang dilakukan adalah deskriptif kuantitaif. Teknik sampling yang digunakan adalah teknik purposive sampling, dengan sampel sebanyak 121 remaja yang ada di kota Bukittinggi. Data pada penelitian ini dianalisis dengan mencari nilai mean dan standar deviasi, dan juga uji analisis kruskal wallis serta mann withney. Strategi ingratiation berada di kategori sedang, intimidation kategori tinggi, self promotion kategori sedang dan rendah, exemplication kategori sedang dan supplication kategori sedang. Hasil uji beda ditemukan hanya pada strategi exemplication yang terdapat perbedaan berdasarkan tingkatan remaja karena nilai $(P)<0,05$, yaitu antara remaja madya dengan remaja akhir.
\end{abstract}

Kata kunci : strategi self presentation, remaja, pengguna instagram

\section{SELF PRESENTATION STRATEGY AMONG ADOLESCENTS INSTAGRAM USERS}

\begin{abstract}
This research presents to see how the strategies carried out by adolescents in conducting self-presentation and also make differences in conducting self-presentation strategies based on adolescents. Each teenager has their own strategy presenting themselves in social media Instagram. The research method used is quantitative descriptive. The sampling technique used was purposive sampling technique, with 121 teenagers as sample in Bukittinggi. The data in this study were analyzed by finding the mean and standard deviation, and also the kruskal wallis and mann withney analysis test. The ingratiation strategy is in the medium category, high category bullying, medium and low self-promotion categories, examples of medium categories and requests for medium categories. Different test results are found only in exemplication strategies where there are differences in adolescent's category because $(P)<0,05$, namely between middle adolescents and late adolescents.
\end{abstract}

Keywords: self presentation strategy, teenagers, instagram users

\section{Pendahuluan}

Sosial media khususnya instagram saat ini sudah menjadi kebutuhan setiap orang, terbuktii dari hasil survey APJII pada tahun 2018 yang mengatakan jika penggunaan sosial media instagram merupakan alasan tertinggi kedua yang paling banyak pengguna dan sering dikunjungi (Asosiasi Penyelenggara Jasa Internet Indonesia, 2018). Pengguna yang paling banyak memakai instagram yaitu dari kalangan remaja sesuai dengan hasil riset yang dilakukan oleh Andrew Perrin (2016). Instagram begitu populer dikalangan remaja karena menyediakan berbagai fitur yang dapat mengekspresikan dirinya kepada orang lain (Smith \& Sanderson, 2015), selain itu juga seseorang dapat berinteraksi dengan pengguna lainnya dengan cara menyukai postingan orang lain dan memberikan komentar terhadap postingan orang lain. Hal itu dikarenakan pada instagram individu dapat mengunggah 
postingan berupa foto, video, ataupun membuat instastory (Heny, 2015), Akan tetapi menurut Tech \& Shamma (2018) postingan yang lebih mungkin untuk mendapatkan banyak like dan comment ialah apabila seseorang mengunggah berupa konten wajah. Instagram juga membuat individu bisa mengunggah postingan berupak teks maupun visual, namun unggahan dalam bentuk visual lebih dominan karena walaupun ingin mengunggah teks maka teks tersebut haruslah berbentuk gambar (Salim, Rahardjo, Tanaya, \& Qurani 2017).

Semakin berkembang dan populernya sosial media berbasis vsiual dan teks seperti instagram, secara tidak sadar bahwa self presentation sangat penting untuk dilakukan, seperti menggunakan filter, mencari sudut yang bagus untuk berfoto sebelum akan di posting ke instagram (Nilsson, 2016). Self presentation sendiri adalah suatu usaha yang dilakukan untuk menimbulkan kesan terhadap orang lain (Jones \& Pitman,1982). Kesan yang ditampilkan kepada orang lain tersebut membutuhkan tahapan seleksi terlebih dahulu agar nantinya sesuai dengan harapan oarang yang akan melihat, sehingga terkesan seperti dibuat-dibuat (Goffman,1956). Self presentation juga dilakukan menggunakan strategi-strategi yang menyebabkan seseorang cenderung tidak menampilkan diri yang sebenarnya (Syafar, 2014).

Melakukan self presentation mempunyai dampak positif dan juga negatif. Dampak positifnya yaitu dapat menjalin komunikasi dengan keluarga dan teman serta memperluas pertemanan, sedangkan dampak negatifnya ialah tidak menjadi diri kita yang sebenarnya serta melakukan hal-hal yang ekstrim seperti operasi plastik (O'Keffe \& Pearson, 2011). Seperti yang terdapat pada sebuah berita yang mengatakan bahwa seorang wanita di LA yang sangat terobsesi ingin foto yang diunggah ke sosial medianya terlihat menarik rela melakukan operasi plastik berkali-kali (Ningrum, 2014), serta wanita di tiongkok memasang foto profil orang lain yang terlihat cantik untuk menipu teman kencan onlinenya agar mendapatkan pria idamannya, akan tetapi saat bertemu secara langsung apa yang ditampilkan wanita di sosial media tersebut berbeda dengan aslinya(Aliana, 2015).

Self presentation di media sosial instagram selain bisa berdampak negatif bagi fisik, juga bisa berdampak negatif secara psikologis, biasanya hal itu sering terjadi pada remaja. Menurut Davis (2012) pengguna sosial media khususnya pada remaja yang terlalu memikirkan self presentation maka akan membuat mereka kehilangan identitas diri yang sebenarnya, karena usia remaja merupakan usia transisi dari anak-anak menuju dewasa serta usia dimana mereka mencari identitas diri mereka. Menurut Murray (dalam Puspitasari, 2015) remaja biasanya menggunakan instagram untuk membuat kesan supaya dilihat dan didengar oleh oleh orang lain dari apa yang di unggahnya, remaja di instagram juga dapat dengan bebas mengeskpresikan dirinya. Penelitian yang dilakukan Prihatiningsih (2017) mengatakan jika remaja menggunakan instagram agar dapat berkomunikasi dan berbagi cerita dengan teman nya, selain itu juga agar mereka bisa mendapatkan teman baru.

Penelitian lain juga mengatakan jika remaja menggunakan instagram sebagai sarana untuk interaksi sosial dimana remaja membagikan hasil kreativitasnya dan menceritakan pengalaman dirinya (Lenhart, 2007). Penelitian yang dilakukan oleh Barker (2009) juga mengatakan jika gadis remaja menggunakan sosial media untuk berkomunikasi dengan teman sebanya nya sedangkan pada laki-laki untuk mencari teman baru. Selanjutnya juga terdapat penelitian yang mengatakan jika sebagian besar remaja mengunggah foto profil dengan gambar yang sekiranya akan menarik perhatian orang lain ( Herring \& Kapidzic, 2011). Berdasarkan penjelasan tersebut, maka penelitian ini bertujuan untuk melihat bagaimana remaja dalam melakukan strategi self presentation, serta apakah terdapat

173 
perbedaan antara tingkatan remaja dalam melakukan strategi self presentation di sosial media instagram.

\section{Metode penelitian}

Penelitian ini menggunakan jenis penelitian deskriptif kuantitatif, yaitu penelitian yang memberikan gambaran lebih detail mengenai gejala dengan data yang ada, kemudian dianalisis dan dinterpretasi (Siregar, 2014), dalam penelitian ini variabel yang akan diteliti yaitu strategi self presentation yang terdiri dari lima strategi yaitu ingratiation, intimidation, self promotion, exemplication dan supplication (Jones\&Pittman,1982).

Teknik sampling yang digunakan dalam penelitian ini adalah purposive sampling, teknik ini dilakukan karena peneliti memiliki kriteria tertentu (Sugiyono,2013) kriteria sampling diantaranya remaja pengguna instagram, Subjek dalam penelitian ini adalah remaja pengguna instagram yang pernah mengunggah foto atau instastory serta pernah memberikan like dan komentar di instagram. Kriteria selanjutnya yaitu remaja yang berada di kota bukittinggi.

\section{Subjek penelitian}

Subjek pada penelitian ini yaitu 121 remaja di Bukittinggi sesuai dengan kriteria yang sudah ditetapkan peneliti yaitu remaja dengan rentang usia 14-21 tahun, yang menggunakan sosial media instagram. Penggunaan instagram sendiri terdapat kriterianya yaitu remaja pernah mengunggah foto atau instastory, serta pernah memberikan komentar dan like terhadap foto yang disukai. 121 remaja tersebut berasal dari kota Bukittinggi diantaranya berasal dari gulai bancah, mandiangin, guguk panjang dan aur birugo tigo baleh.

\section{Variabel dan instrumen penelitian}

Variabel dalam penelitian ini yaitu strategi self presentation. Skala yang digunakan yaitu skala self presentation oleh Lee,et al (1999), dengan 4 pilihan jawaban yaitu (Sangat setuju, Setuju, Tidak setuju, Sangat tidak setuju) yang terdapat aitem favorable dan unfavorable. Aitem yang digunakan sebanyak 50 aitem. 50 aitem tersebut kemudian dilakukan uji coba dan mendapatkan hasil bahwa terdapat 15 aitem yang gugur dan 35 aitem yang valid dengan rentang nilai 0,220 hingga 0,633, setelah itu dilakukan kembali analisis faktor yang mana terdapat pula 2 aitem lagi yang gugur dan tersisa 33 aitem karena nilai $\mathrm{P}<0,50$.

Tabel 1. uji validitas dan reliabilitas

\begin{tabular}{cccc}
\hline Alat ukur & Jumlah aitem & Validitas & Reliabilitas \\
\hline Self presentation & 35 & 0,220 & 0,824 \\
\hline
\end{tabular}


Trisna Septia Ningsih dan Gumi Langerya Rizal

Tabel 2. Analisis faktor strategi self presentation

\begin{tabular}{lllll}
\hline \multicolumn{1}{c}{ Strategi } & \multicolumn{1}{c}{ Jumlah aitem } & \multicolumn{1}{c}{ KMO } & \multicolumn{1}{c}{ MSA } & \multicolumn{1}{c}{ Loading factor } \\
\hline Ingratiation & 33 & 0,744 & $0,645-0,829$ & $0,543-0,773$ \\
Intimidation & 33 & 0,628 & $0,620-0,641$ & $0,715-0,743$ \\
Self promotion & 33 & 0,825 & $0,786-0,853$ & $0,577-0,820$ \\
Exemplication & 33 & 0,597 & $0,574-0,69$ & $0,719-0,977$ \\
Supplication & 33 & 0,794 & $0,725-0,843$ & $0,616-0,825$ \\
\hline
\end{tabular}

\section{Prosedur dan analisis data}

Tahapan pertama yang dilakukan dalam penelitian ini adalah persiapan, dimana peneliti mencari fenomena yang terkait dengan tema. Setelah menemukan fenomena, peneliti kemudian membuat rumusan masalah yang tepat. Selanjutnya peneliti juga mencari populasi, dan teknik sampling yang tepat, dan yang terakhir peneliti mencari alat ukur yang sesuai dengan variabell tersebut.

Tahapan kedua yaitu pelaksanaan penelitian, alat ukur yang sudah didapatkan kemudian dilakukan proffesional judgement oleh dua orang dosen jurusan psikologi universitas negeri padang. Setelah mendapat persetujuan dari pihak dosen, selanjutnya dilakukan uji validitas dan reliabilitas menggunakan cronbach alpha dan analisis faktor dengan bantuan SPSS for windows version 25 . Aitem yang sudah teruji validitas dan reliabilitasnya kemudian disusun kembali untuk kemudian dapat digunakan dalam penelitian.

Tahapan yang terakhir yaitu analisis data, dalam penelitian ini data yang telah didapatkan kemudian dilakukan skoring dengan mencari nilai mean dan standar deviasi per-strategi dan kemudian dikelompokkan dengan kategori tinggi, sedang, dan rendah. Kemudian melakukan uji normalitas untuk melihat apakah data terdistribusi normal atau tidak. Selanjutnya melakukan uji non-parametrik kruskal wallis dan mann withney dengan bantuan SPSS for window version 25.

\section{Hasil Penelitian}

Penelitian ini dilakukan dengan menyebarkan angket secara langsung dan juga secara online. Penyebaran kuesioner secara online dilakukan melalui google form serta penyebaran kuesioner secara langsung yang dilakukan di kota bukittinggi, yang kemudian memperoleh subjek sebanyak 121 . Berikut merupakan hasil dari nilai mean dan juga pengkategorian yang dilakukan pada masing-masing strategi (ingratiation, intimidation, self promotion, exemplication dan supplication) serta uji analisisis kruskal wallis dan mann withney dari penelitian yang dilakukan. 
Tabel 3. Nilai rerata dan standar deviasi strategi self presentation

\begin{tabular}{lllllll}
\hline \multicolumn{7}{c}{$\begin{array}{c}\text { Statistik Deskriptif } \\
\text { Mean empirik }\end{array}$} \\
\hline Ingratiation & $\mathrm{N}$ & Range & Min & Max & Mean & Std. Deviation \\
Intimidation & 121 & 19 & 17 & 36 & 28,14 & 3,678 \\
Self promotion & 121 & 7 & 3 & 10 & 6,099 & 1,624 \\
Exemplication & 121 & 16 & 7 & 23 & 15,88 & 3,126 \\
Supplication & 121 & 8 & 4 & 12 & 7,77 & 1,309 \\
& 121 & 18 & 9 & 27 & 16,47 & 3,88 \\
& $\mathrm{~N}$ & \multicolumn{7}{c}{ Mean hipotetik } & & & \\
Ingratiation & 121 & Range & Min & Max & Mean & Std.deviation \\
Intimidation & 121 & 9 & 11 & 44 & 27,5 & 5,5 \\
Self promotion & 121 & 21 & 3 & 12 & 7,5 & 1,5 \\
Exemplication & 121 & 9 & 3 & 28 & 17,5 & 3,5 \\
Supplication & 121 & 27 & 9 & 36 & 7,5 & 1,5 \\
& \multicolumn{7}{c}{} & 92,5 & 4,5 \\
\hline
\end{tabular}

Berdasarkan tabel diatas dapat diketahui bahwa diperoleh nilai mean empirik $(28,14)$ dan mean hipotetik $(27,5)$ yang artinya nilai mean empirik lebih besar dibandingkan nilai mean hipotetik pada strategi ingratiation. Strategi intimidation diperoleh nilai mean empirik yang lebih kecil dibandingkan nilai mean hipotetik ( $\mu$ e $6,09<\mu \mathrm{h} 7,5$ ). Selanjutnya pada Strategi self promotion diperoleh nilai mean empirik yang lebih kecil dibandingkan dengan nilai mean hipotetik ( $\mu \mathrm{e} 15,88<$ $\mu \mathrm{h} 17,5)$, strategi exemplication diperoleh nilai mean empirik yang lebih besar dibandingkan dengan nilai mean hipotetik ( $\mu$ e $7,77<\mu \mathrm{h} 7,5)$. Terakhir yaitu strategi supplication diperoleh nilai mean empirik lebih kecil dibandingkan dengan nilai mean hipotetik ( $\mu$ e $16,47<\mu \mathrm{h} 22,5$ ).

Tabel 4. Kategorisasi strategi ingratiation dan intimidation

\begin{tabular}{lllll}
\hline \multirow{2}{*}{ Kategori } & \multicolumn{2}{c}{ Ingratiation } & \multicolumn{2}{c}{ Intimidation } \\
\cline { 2 - 5 } & Frekuensi & Presentatse & Frekuensi & Presentase \\
\hline Tinggi & 34 & $28,09 \%$ & 50 & $41,32 \%$ \\
Sedang & 68 & $56,19 \%$ & 50 & $41,32 \%$ \\
Rendah & 19 & $15,7 \%$ & 21 & $17,35 \%$ \\
\hline
\end{tabular}


Trisna Septia Ningsih dan Gumi Langerya Rizal

Tabel 5.kategorisasi strategi self promotion, exemplication dan supplication

\begin{tabular}{lllllll}
\hline \multirow{2}{*}{ Kategori } & \multicolumn{2}{c}{ Self promotion } & \multicolumn{2}{c}{ exemplication } & \multicolumn{2}{c}{ Supplication } \\
\cline { 2 - 7 } & Frekuensi & presentase & Frekuensi & Presentase & Frekuensi & Presentase \\
\hline Tinggi & 30 & $24,7 \%$ & 35 & $28,9 \%$ & 25 & $20,66 \%$ \\
\hline Sedang & 77 & $63,6 \%$ & 66 & $54,5 \%$ & 73 & $60,33 \%$ \\
\hline Rendah & 14 & $11,5 \%$ & 20 & $16,5 \%$ & 23 & $19 \%$ \\
\hline
\end{tabular}

Setelah mendapatkan nilai mean dan standar deviasi, maka dilakukan pengkategorian pada setiap strategi self presentation dengan kategori tinggi, sedang, dan rendah. Berdasarkan hasil tabell 4 dan 5 diatas dapat diketahui bahwa pada strategi ingratiation terdapat 34 subjek dengan kategorii tinggi, 68 subjek dengan kategori sedang dan 19 subjek dengan kategori rendah. Sedangkan pada strategi intimidation kategori tinggi terdapat 50 subjek, sama halnya dengan kategori sedang yang memperoleh 50 subjek, dan 21 subjek pada kategori rendah. Strategi intimidation ini merupakan strategi paling banyak dilakukan oleh remaja pada kategori tinggi dibandingkan dengan strategii lainnya.

Kemudian pada strategi self promotion kategori tinggi diperoleh sebanyak 30 subjek, kategori sedang sebanyak 77 subjek dan kategori rendah terdapat 14 subjek. Strategi self promotion merupakan strategi yang paling banyak dilakukan remaja pada kategori sedang sekaligus kategori rendah dibandingkan dengan strategi lainnya. Pada strategi exemplication terdapat 35 subjek pada kategori tinggi, 66 subjek dengan kategori sedang dan 20 subjek dengan kategori rendah. Strategii terakhir terdapat 25 subjek pada kategori tinggi dalam melakukan strategi supplication, 73 subjek dengan kategori sedang dan terdapat 23 subjek dengan kategori rendah.

Uji normalitas yang dilakukan pada penelitian ini diperoleh dari 5 strategi yang digunakan hanya terdapat 1 strategi yang data terdistribusi dengan normal, yaitu strategi ingratiation dengan nilai $(P) 0,200$. Sedangkan strategi yang lain data tidak terdistribusi dengan normal karena nilai $(P)<$ 0,05 . Oleh karena itu peneliti menggunakan uji non parametrik kruskal wallis dan mann withney untuk melihat perbedaan remaja dalam melakukan strategi self presentation berdasarkan tingkatan remaja itu sendiri, yaitu remaja awal, madya dan akhir.

Tabel 6. Tabel kruskal wallis dan mann withney

\begin{tabular}{lll}
\hline \multicolumn{1}{c}{ Strategi } & \multicolumn{1}{c}{ Kruskal wallis (sig) } & \multicolumn{1}{c}{ Mann withney (sig) } \\
\hline Ingratiation & $1.097(, 578)$ & - \\
Intimidation &, $353(, 838)$ & - \\
Self promotion & $1,097(, 578)$ & - \\
Exemplication & $6,969(, 031)$ & $1157,000(, 011)$ \\
Supplication &, $167(, 920)$ & - \\
\hline
\end{tabular}

Berdasarkan tabel diatas dapat diketahui bahwa hanya pada strategi exemplication ditemukan adanya perbedaan berdasarkan tingkatan remaja, karena nilai $\mathrm{P}<0,05$. Diketahui dari hasil uji mann 
withney perbedaan terletak pada tingakatan remaja madya dengan remaja akhir. Sedangkan pada strategi lainnya yaitu ingratiation, intimidation, self promotion dan supplication tidak ditemukan adanya perbedaan dalam remaja melakukan strategi self presentation jika dilihat dari tingkatan remaja karena nilai $P>0,05$.

\section{Pembahasan}

Berdasarkan penelitian yang dilakukan, dapat dilihat bahwa masing-masing strategi yang dilakukan oleh remaja memiliki kecenderungan tersendiri. Seperti hal nya strategi intimidation yang merupakan strategi paling banyak dalam kategori tinggi yang dilakukan oleh remaja dengan jumlah 50 subjek. Hal ini sesuai dengan penelitian yang dilakukan oleh Peluchette \& Karl (2008) yang mengatakan jika remaja cenderung tidak memperdulikan apa yang diinginkan oleh orang lain dalam memperlihatkan kesan agar terlihat menarik di sosial media. Remaja dalam melakukan strategii intimidation juga tidak ditemukan adanya perbedaan dari segi tingkatan remaja.

Selanjutnya pada strategi supplication, yang merupakan strategi paling banyak kedua setelah strategi self promotion yang dilakukan oleh remaja dalam kategori sedang dengan jumlah 73 subjek. Strategi supplication sendiri yaitu memberikan kesan seperti seorang yang lemah dan bergantung kepada orang lain (jones \& Pittman, 1982). Sesuai dengan penelitian yang dilakukan oleh Puspitasari (2015) jika masa remaja merupakan masa yang membutuhkan dukungan dari orang lain, dengan cara menampilkan keadaan dirinya di sosial media agar mendapatkan simpati dan dukungan dari orang lain. Sama hal nya dengan penelitian yang dilakukan oleh Prihatiningsih (2017) yang mengatakan jika remaja menggunakan instagram untuk menunjukkan keadaan dirinya saat sedang sedih, galau atau stres karena adanya kebutuhan integrasi personal. Kemudian, tidak ditemukan adanya perbedaan remaja dalam melakukan strategi supplication berdasarkan tingkatan remaja.

Berikutnya strategi self promotion, yang merupakan strategi paing banyak dilakukan remaja dalam kategori rendah dibandingkan dengan strategi lainnya. Subjek yang diperoleh berjumlah 14. Strategi ini dilakukan agar seseorang terlihat kompeten dan mendapatkan pengakuan dari orang lain (Jones \& Pittman, 1982). Hal tersebut didukung dengan penelitian yang dilakukan oleh Puspitasari (2015) yang mengatakan bahwa remaja cenderung ingin mendapatkan pengakuan dari orang lain dan juga ingin dihargai. Pada penelitian ini juga ditemukan bahwa tidak ada perbedaan pada remaja dalam melakukan self presentation strategi self promotion berdasarkan tingkatan remaja.

Strategi selanjutnya yaitu ingratiation yang merupakan strategi paling sering dilakukan dalam self presentation, yaitu seseorang berusaha menampilkan kesan kepada orang lain sebagai seseorang yang menarik dan menyenangkan (Jones \& Pittman, 1982). Hasil dari penelitian ini menemukan bahwa remaja paling banyak berada di kategori sedang, dengan jumlah subjek sebanyak 68 . Hasil penelitian sebelumnya juga mengatakan jika seseorang sengaja untuk menampilkan dirinya dengan mengunggah foto yang imut agar terlihat menarik oleh pengguna lainnya (Nillson,2006). Penelitian lain juga mengatakan jika individu menampilkan dirinya sebagai seseorang yang humoris agar terlihat menarik (Manago et al, 2008). Penelitian ini juga ditemukan tidak adanya perbedaan pada remaja dalam melakukan strategi ingratiation berdasarkan tingkatan remaja.

Strategi yang terakhir yaitu strategi exemplication yang dilakukan dengan menampilkan kesan terlihat sebagai orang yang bermoral dan selalu menampilkan hal yang positif sehingga terhindar dari penolakan sosial (Jones \& Pittman, 1982). Hasil dalam penelitian ini yaitu remaja berada pada kategori sedang dengan jumlah 66 subjek. Sesuai dengan penelitian yang dilakukan oleh Puspitasari (2015) 
yang mengatakan jika remaja cenderung ingin menampilkan diri yang baik dan menghindari penilaian buruk dari orang lain, baik dalam hal pertemanan maupun kegiatan yang dilakukannya. Dalam strategi excemplication, terdapat adanya perbedaan remaja berdasarkan tingkatan remaja, yaitu pada remaja madya dengan remaja akhir. Hal tersebut bisa saja terjadii karena baik pada remaja madya dan remaja akhir memiliki karakteristik yang berbeda, seperti remaja madya yang diusia tersebut sangat membutuhkan teman yang membuat mereka memperlihatkan sisi positifnya, selain itu juga remaja madya merupakan masa dalam seseorang mencari identitas diri (Putro,2017). Sedangkan pada remaja akhir lebih stabil secara psikis dan juga lebih matang dalam melakukan sesuatu, sehingga bisa lebih berfikir realistis dan mengontrol fikiran dan perasaan. Sehingga pada remaja akhir dapat berfikir dengan realistis kapan dan dimana strategi exemplication dapat dilakukan agar menjadi contoh yang baik bagi orang lain.

\section{Kesimpulan}

Berdasarkan penelitian yang telah dilakukan, maka dapat disimpulkan sebagai berikut:

1. Strategi intimidation merupakan strategi paling banyak dilakukan remaja dalam kategori tinggi dibandingkan dengan strategi lainnya. strategi self promotion merupakan strategi paling banyak dilakukan remaja dalam kategori sedang sekaligus dalam kategori rendah dibandingkan dengan strategi lainnya. Sedangkan pada strategi excemplication, supplication dan ingratiation yang dilakukan oleh remaja masing-masing cenderung berada dikategori sedang.

2. Hasil uji beda berdasarkan tingkatan usia remaja dalam melakukan strategi self presentation sebagian besar strategi menunjukka tidak adanya perbedaan, kecuali strategi exemplication yang memiliki perbedaan yaitu pada remaja madya dengan remaja akhir.

\section{Daftar pustaka}

Asosiasi penyelenggara jasa internet indonesia (2018). Penetrasi \& profil perilaku pengguna internet indonesia.

Aliana. S. S. (2015). Wanita ini babak belur dipukuli teman kencan online. Diakses pada tanggal 06 februari 2015 diperoleh dari http://teknologi.news.viva.co.id/news/read/586439

Barker, V. (2009). Older adolescents ' motivations for social network site use : the influence of gender , group identity, and collective self esteem, 12(2). https://doi.org/10.1089/cpb.2008.0228

Davis, K. (2012). Tensions of identity in a networked era: young people's perspective on the risks and rewards of online self-expression, 634-651. https://doi.org/10.1177/1461444811422430

Goffman, E. (1956). The presentation of self in everyday life.

Herring, S. C., \& Kapidzic, S. (2011). Gender , communication, and self-presentation in teen chatrooms revisited: have patterns changed?, 17, 39-59. https://doi.org/10.1111/j.1083$\underline{6101.2011 .01561 . x}$

179 
Heny, G. (2015). Korelasi media sosial instagram dengan presentasi diri mahasiswa jurusan ilmu komunikasi universitas riau, 2(2), 1-15.

Jones, E.E.,\& Pitman, T. S. (1982). Toward a general theory of strategic self-presentation.

Lenhart, A., \& Madden, M. (2007). Teens, Privacy \& Online Social Networks How teens manage their online identities and personal information in the age of Findings.

Lee, S., Quigley, B. M., Nesler, M. S., Corbett, A. B., \& Tedeschi, J. T. (1999). Development of a selfpresentation tactics scale. Perspnality and Individual Differences, 26.

Manago, A. M., Graham, M. B., Green, P. M., \& Salimkhan, G. (2008). Journal of Applied Developmental Psychology Self-presentation and gender on MySpace, 29, 446-458. https://doi.org/10.1016/j.appdev.2008.07.001

Nilsson, M. (2016). "First, let me take a selfie"-young adults self presentation on instagram,1-51.

Ningrum, D.W. (2014). demi selfie cantik, triana operasi plastik ratusan juta rupiah. Diakses tanggal 07 februari 2015 diperoleh dari http://tekno.liputan6.com/read/2042789

O'Keffe, G., \& Pearson, K. (2011). Clinical Report - the impact of social media on children , adolescents , and families abstract. american academy of pediatrics. https://doi.org/10.1542/peds.2011-0054

Peluchette, J. O. Y., Karl, K., \& Ph, D. (2008). Student Attitudes Regarding Use and Appropriateness of Content, 11(1), 95-97. https://doi.org/10.1089/cpb.2007.9927

Perrin, Andrew.(2016). Social Media Usage:2005-2015 65\% of Adults Now Use Social Networking Sites-A Nearly Tenfold Jump In The Past Decade, US : Pew Reseach center.

Prihatiningsih, W. (2017). Motif penggunaan media sosial instagram di kalangan remaja, (April), 5165.

Puspitasari, F. I. (2015). Kebutuhan remaja untuk mengirim foto atau video di instagram, 2(2), 461472.

Putro, K. Z. (2017). Memahami Ciri dan Tugas Perkembangan Masa Remaja, 17, 25-32.

Salim, F., Rahardjo, W., Tanaya, T., \& Qurani, R. (2017). Are self-presentation of instagram users influenced by friendship-contingent self-esteem and fear of missing out ?, 21(2), 70-82. https://doi.org/10.7454/mssh.v21i2.3502

Siregar, T, (2014). Statistika deskriptif untuk penelitan: dilengkapi perhitungan manual dan aplikasi 
Trisna Septia Ningsih dan Gumi Langerya Rizal

SPSS versi 17. Jakarta:Rajawali pers

Smith, L. R., \& Sanderson, J. (2015). I' m going to instagram it! an Analysis of athlete self-presentation on instagram, 59(2), 342-358. https://doi.org/10.1080/08838151.2015.1029125

Sugiyono. (2013). Metode penelitian kuantitatif, kualitatif. Bandung: alfabet

Tech, G., \& Shamma, D. A. (2016). Faces engage us : photos with faces attract more likes and comments on instagram, (June). https://doi.org/10.1145/2556288.2557403 